\title{
Dengue epidemic typology and risk factors for extensive epidemic in Amazonas state, Brazil, 2010-2011
}

\author{
Daniel Barros de Castro 1,2, Vanderson Souza Sampaio ${ }^{1,3}$, Bernardino Cláudio de Albuquerque ${ }^{1}$, \\ Rosemary Costa Pinto ${ }^{1}$, Megumi Sadahiro ${ }^{1}$, Ricardo Augusto dos Passos ${ }^{1,4}$, Cristiano Fernandes da Costa \\ and José Ueleres Braga ${ }^{2,5,6^{*}}$
}

\begin{abstract}
Background: Dengue is the most prevalent arboviral disease affecting humans. The frequency and magnitude of dengue epidemic have significantly increased over recent decades. This study aimed to identify dengue epidemic types and risk factors for the extensive epidemics that occurred in 2010-2011, across the municipalities of Amazonas state, Brazil.

Methods: Using an ecological approach, secondary data were obtained from the dengue fever surveillance system. Epidemic waves were classified according to three indices: duration, intensity, and coverage. A hierarchical model of multiple logistic regression was used for the identification of risk factors, with the occurrence of extensive dengue epidemic.

Results: During the study period, dengue virus affected 49 of the 62 Amazonas municipalities. In 22 of these, the epidemics were of high intensity, wide range, and long time span, and therefore categorized as "extensive epidemics". The final multivariable model revealed a significant association between extensive dengue epidemics occurrence and the average number of days with precipitation (adjusted $\mathrm{OR}=1.40,95 \% \mathrm{Cl}: 1.01-1.94$ ) and the number of years with infestation (adjusted $\mathrm{OR}=1.53,95 \% \mathrm{Cl}: 1.18-1.98$ ).

Conclusions: Our results indicate that it is crucial to integrate vector control, case management, epidemiological investigation, and health education, in order to respond to the growing threat of multiple mosquito-borne diseases, such as dengue, Zika and chikungunya, which are highly prevalent in the South America region.
\end{abstract}

Keywords: Dengue epidemics classification, Socioeconomic, Environment, Climate, Amazon

\section{Background}

Dengue is a acute febrile disease, transmitted by arthropod vectors, and caused by four different virus (DENV1, DENV-2, DENV-3, DENV-4). Dengue virus infections may be asymptomatic or lead to a range of clinical presentations, even death [1]. The clinical manifestations include acute fever, frontal headache, retroocular pain, muscle and joint pain, nausea, vomiting, and rash [2,3]. The illness, generally, is self-limited and lasts

* Correspondence: veleres@gmail.com

2Escola Nacional de Saúde Pública Sérgio Arouca - Fiocruz, Rio de Janeiro, Brazil

${ }^{5}$ Instituto de Medicina Social - UERJ, Rio de Janeiro, Brazil

Full list of author information is available at the end of the article approximately for one week. Patients may eventually develop severe disease, characterized by acute fever with minor or major bleeding, evidence of plasma leakage, and organ involvement [4].

Dengue infections occur in more than 100 countries, reaching approximately 50 million cases each year [5]. In the Americas, the occurrence of recurring dengue outbreaks every 3-5 years with an increasing number of cases over time shows the transition from an endemicepidemic state to a highly endemic state in recent years [6]. In the state of Amazonas, Brazil, although there is a high density of mosquitoes throughout the seasons, there is usually a peak of the disease in the first half of the year [7-9]. Since 1998, when the dengue virus was 
first detected in Manaus, Amazonas state capital, an increasing number of countryside municipalities have been affected by dengue epidemics. During 2010 and 2011, dengue disease affected 49 of the 62 municipalities in Amazonas [9].

Dengue fever has been shown to spread by epidemic waves, that is, the number of reported cases suddenly increases until reaching a peak and then gradually decreases until the epidemic ends [10]. However, the magnitude of dengue epidemics is variable. Epidemics appear to largely reflect susceptibility of the human population to circulating serotypes and mosquito density; however, they are also affected by climatic, environmental, meteorological, social and demographic conditions [11, 12].

Hopp and Foley [13] built a model based on climatic variables in order to predict the mosquito population size, which was related to the number of dengue cases in South Asia and Central America. Hales et al. [14] investigated the role of meteorological covariates in determining the pattern of spatial distribution of dengue cases, concluding that average vapor pressure was the main predictor of dengue distribution. According to the authors, the average vapor pressure, which is a measure of humidity, is high only where rainfall and temperatures are high, and these are conditions that are conducive to breeding and survival of vector populations, and rapid replication of the virus [14].

In addition to recognizing epidemics, it is important to be aware of epidemic magnitude, as milder epidemics have less damaging consequences for the population and their control can be achieved with less complex measures. Conversely, extensive epidemics are more difficult to control, entails a greater financial burden and cause more damage to the population, due to the increased mortality rate and the occurrence of severe cases and temporary disability which lead to significant economic losses [14].

Although much is known about climatic and environmental conditions (temperature and precipitation) and population characteristics (vulnerability to circulating subtypes) associated with epidemic occurrence [6], there is a lack of knowledge about the conditions that determine the large scale, extent and duration of epidemics, that is, the causes of "extensive dengue epidemics".

Wen et al. [15] criticized the use of dengue annual incidence as an only measure of epidemic wave intensity and justified the adoption of different measures to characterize epidemic severity. The authors suggested three relevant indicators: (i) frequency index, defined as the number of weeks with recorded cases divided by the total number of weeks of the study period; (ii) duration index, defined as the number of weeks with recorded cases divided by the number of epidemic waves; (iii) intensity index, the incidence rate divided by the number of epidemic waves.

The recognition of factors (modifiable and uncontrollable) associated with extensive epidemics is fundamental for the adoption of measures aimed at reducing modifiable causes. Furthermore, the identification of extensive epidemic-likely scenarios would enable control program intensification or the implementation of different strategies to mitigate the effects of the epidemic.

\section{Methods}

This study aimed: (i) to identify dengue epidemic types, and (ii) risk factors for extensive epidemics occurring in 2010-2011 in the municipalities of Amazonas state, Brazil.

The state of Amazonas is located in Northern Brazil and is the largest federative unit, with an area of $1,559,161 \mathrm{~km}^{2}$, divided into 62 municipalities and 9 health regions (Fig. 1). It counts 3,483,985 inhabitants, of whom 79\% lived in urban zones, in 2010. Approximately $52 \%(1,802,525$ inhabitants) of the state's population resided in the capital Manaus [16]. The general population density in the state was 2.2 inhabitants $/ \mathrm{km}^{2}$ and 158 inhabitants $/ \mathrm{km}^{2}$ in the capital [16]. The predominant climate is equatorial, characterized by high temperatures and high rainfall indices [17].

We conducted an ecological study using secondary data from dengue fever surveillance system. Amazonas state municipalities and calendar months were considered as the units of analysis.

Data on dengue cases were extracted from the Notifiable Diseases Information System (called SINAN) provided by the Health Surveillance Foundation (called FVS-AM) of the Health Department of the State of Amazonas. We included all records of dengue cases in SINAN, reported between January 1 2001, and December 31 2011, defined as classical dengue, dengue with complications, dengue hemorrhagic fever or dengue shock syndrome. The classification of the cases followed the criteria established by the Ministry of Health, in accordance with the World Health Organization (WHO) recommendations [18]. Dengue cases were georeferenced by the municipality of patient residence.

The population resident in the municipalities and regions was obtained from the censuses conducted by the Brazilian Institute of Geography and Statistics (IBGE) in 2000 and 2010. From these data, population estimates for the inter-census years were calculated using a linear interpolation technique [19].

\section{Dengue epidemic typology and extensive epidemic definition}

The identification of epidemic periods was performed based on analysis of statistical process control charts 


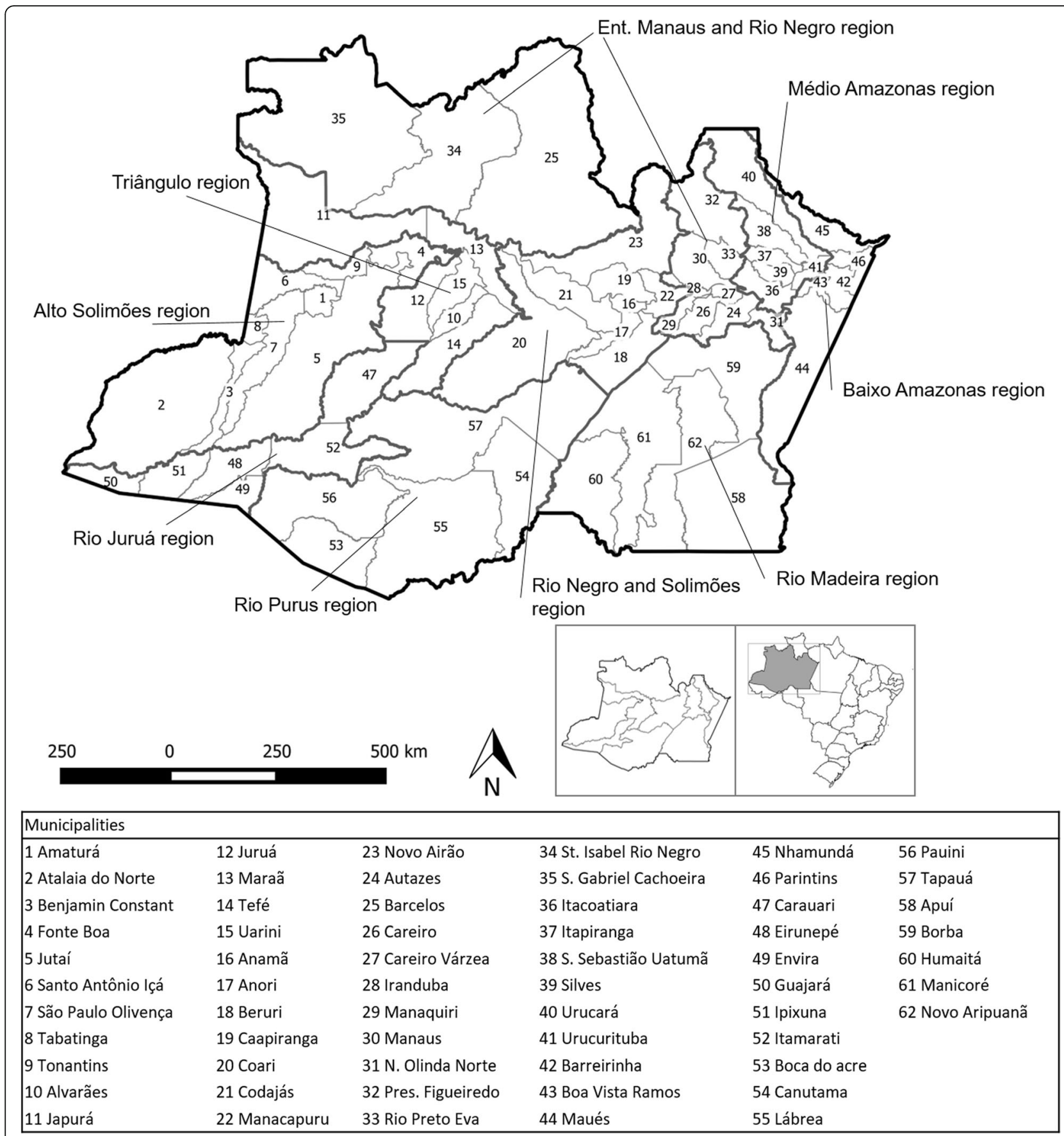

Fig. 1 Municipalities and health regions of the state of Amazonas

prepared for each municipality. The control charts were constructed according to the following steps: (i) calculation of the average monthly incidence rate for the period 2001 to 2010; (ii) visual inspection of the monthly epidemic curve of dengue disease in each municipality to identify putative epidemic months (PEM) with a substantial increase in incidence rates; (iii) determination of the epidemic months, defined by an epidemic onset (the PEM with a positive change in the incidence rate greater than $60 \%$ of the incidence of the preceding month) and a termination point (the PEM with a negative change in the incidence rate greater than $60 \%$ of the incidence of the preceding month; (iv) excluding periods (epidemic months) with high incidence rates; (v) calculation of the expected maximum incidence rate corresponding to the sum of the average incidence rate with 1.96 the standard deviation of this rate; (vi) identification of the epidemic months, characterized by a monthly incidence rate in 
2010 and 2011 exceeding the expected maximum limit of the control chart.

An epidemic wave was defined as a set of consecutive epidemic months (more than 1 month) when the epidemic occurred in a given municipality or the epidemic lasting 1 month with incidence greater than 10 cases / 100 thousand inhabitants. In this study, we propose a typology of epidemic that includes two measures used in the method described by Wen et al. [15] in combination with a third aspect relating to the spatial extent of the epidemic. We defined the extent of the epidemic wave based on the variation of incidence rates calculated for each month, consistently with the method reported by Parker and Holman [11]. Epidemic waves were classified according to three indices: duration, intensity, and coverage.

The duration index $\alpha$ was calculated by the ratio of the sum of epidemic months (EM) divided by the number of epidemic waves (EW) observed in each municipality, where $\mathrm{i}$ indicates the index of the epidemic wave.

$$
\alpha=\frac{\sum_{1}^{i} E M}{n E W}
$$

The intensity index $\beta$ was calculated by the ratio of the sum of the average monthly incidence rates (IR) of each epidemic wave and the number of epidemic waves $(E W)$ observed in each municipality, where $i$ indicates the epidemic wave index.

$$
\beta=\frac{\sum_{1}^{i} I R}{n E W} .
$$

The spatial coverage index $\Upsilon$ was calculated by the ratio of the number of municipalities with epidemic waves (MEW) in a given region and the total number of municipalities in the region (TMR).

$$
\Upsilon=\frac{n M E W}{n T M R}
$$

According to the variation of the values of each index, three categories were defined and a score ranging from 1 to 3 was assigned (Table 1 ).

From the sum of the scores for each criterion, a global score was calculated for each municipality, ranging from 1 to 9. Ultimately, the municipalities with an overall score of 8 or higher were considered with "extensive dengue epidemics" (EDE).

\section{Study variables}

The following socioeconomic information was examined: illiteracy rate, municipal human development index (HDI), Gini index of income, average household income per capita, proportion of the poor population, unemployment rate of the population aged 18 or over, proportion of population in households with bathroom and piped water, proportion of population in households with garbage collection, and proportion of urban population. These indicators were obtained from the 2010 demographic census. The definition and calculation of these indicators is detailed in Additional file 1: Table S1.

The meteorological variables used were: wind speed, insolation, days with precipitation, precipitation, minimum temperature, maximum temperature, relative humidity, and compensated temperature. The river quota parameters analyzed were: maximum quota, minimum quota, and average quota. The meteorological and river quota variables analyzed refer to the period from January 2010

\begin{tabular}{|c|c|c|c|}
\hline Criterion & Feature & Definition & Score \\
\hline \multirow[t]{3}{*}{ Duration (based on index a) } & Low & Up to 3 epidemic months & 1 \\
\hline & Middle & With 4 to 6 epidemic months & 2 \\
\hline & High & Greater than 6 epidemic months. & 3 \\
\hline \multirow[t]{3}{*}{ Intensity (based on the $B$ index) } & Low & $\begin{array}{l}\text { Incidence rates in epidemic months less than } 10 \text { cases / } 100 \\
\text { thousand inhabitants. }\end{array}$ & 1 \\
\hline & Middle & $\begin{array}{l}\text { Incidence rates in epidemic months between } 10^{\text {a }} \text { and } 100 \text { cases / } 100 \\
\text { thousand inhabitants. }\end{array}$ & 2 \\
\hline & High & $\begin{array}{l}\text { Incidence rates in epidemic months above } 100^{\text {b }} \text { cases / } 100 \\
\text { thousand inhabitants }\end{array}$ & 3 \\
\hline \multirow[t]{3}{*}{ Coverage (based on index $\curlyvee$ ) } & Limited & $\begin{array}{l}\text { Up to } 1 / 3 \text { of the municipalities in the region presented epidemic } \\
\text { months }\end{array}$ & 1 \\
\hline & Moderated & $\begin{array}{l}\text { From } 1 / 3 \text { and } 2 / 3 \text { of the municipalities in the region presented epidemic } \\
\text { months }\end{array}$ & 2 \\
\hline & Wide & Greater than $2 / 3$ of the municipalities in the region had epidemic months & 3 \\
\hline
\end{tabular}
to December 2011, same period that extensive dengue

Table 1 Scores according to criteria categories for epidemics classification

${ }^{a} 1$ st quartile of distribution of dengue incidence rates; ${ }^{b} 3$ th quartile of distribution of dengue incidence rates 
epidemics were studied. See detailed information on obtaining these indicators in Additional file 1: Table S2.

Vector control actions were measured by Stegomyia indices widely used in the scientific literature [20], which are: average annual proportion of home visit targets achieved; number of years with an achieved target of 5 home visits; number of years with infestation; appropriate ratio of number of agents per building; appropriate ratio of number of supervisors by health agent; adequate ration of supervisors and agents per building; household infestation mean index for the period; and number of years with household infestation mean index greater than $1 \%$. These indicators refer to annual averages recorded between 2010 and 2011. The vector control activities data were obtained from the FVS's Department of Environmental Surveillance and Disease Control. See detailed information on obtaining these indicators in Additional file 1: Table S3.

\section{Statistical analysis}

We performed an analysis of completeness and inconsistencies in the dengue database. Records with similarities regarding patient name, date of birth, and mother's name, and those with a period of less than 60 days between reporting dates were identified as duplicate records, and were excluded.

Summary measures (mean, standard deviation, minimum and maximum values) were used to describe the distribution of study variables. A hierarchical model of multiple logistic regression was used for the identification of risk factors, with the occurrence of extensive dengue epidemic, defined above, as the as the outcome variable. Associations between socioeconomic, meteorological, and performance characteristics of dengue surveillance services in the municipalities of Amazonas and the outcome (EDE) were initially analyzed separately for each group (hierarchical level). Subsequently, for the construction of the final model, we selected the explanatory variables showing an association with the outcome for a level of significance of 0.20 by stepwise technique backward mode. Variables associated with the outcome at a significance level of 0.05 remained in the final model. The multicollinearity between the explanatory variables selected for the final model was analyzed using the variance inflation factor test, and those variables with VIF greater than 10 were considered collinear and excluded of the model. Crude and adjusted odds ratios of the association between the outcome and the explanatory variables were calculated. Statistical package STATA

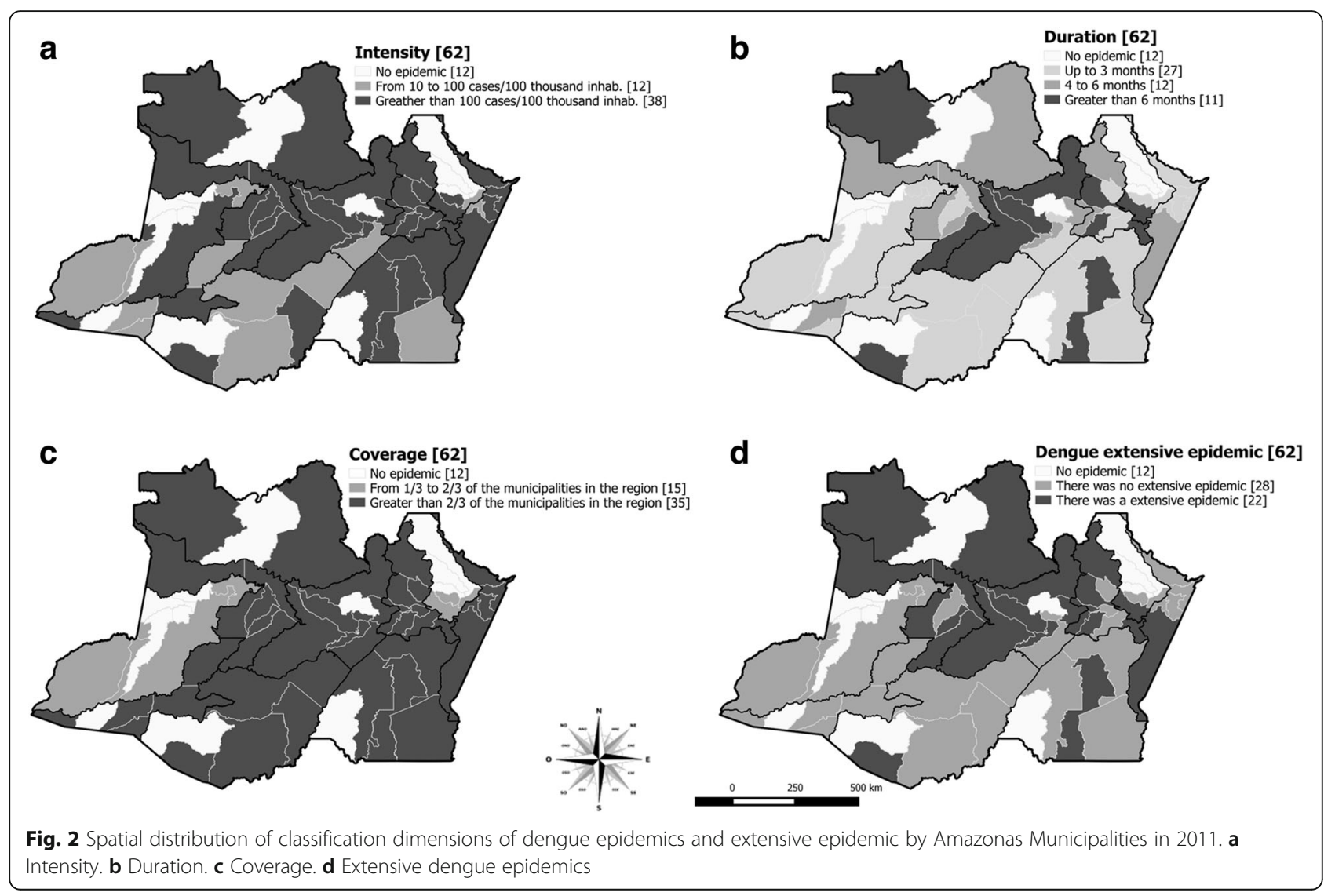


Table 2 Socioeconomic profile, meteorological findings, river quota, and operational characteristics of dengue surveillance services in Amazonas municipalities

\begin{tabular}{|c|c|c|c|c|c|}
\hline Feature & $\mathrm{N}$ & Mean & SD & Max. & Min. \\
\hline \multicolumn{6}{|l|}{ Socioeconomic profile } \\
\hline Illiteracy rate & 62 & 20.9 & 9.7 & 40.7 & 4.0 \\
\hline Income Gini Index & 62 & 0.6 & 0.1 & 0.8 & 0.5 \\
\hline Proportion of poor & 62 & 53.0 & 12.0 & 74.2 & 12.9 \\
\hline Per capita income & 62 & 251.3 & 98.3 & 790.3 & 122.2 \\
\hline Unemployment rate & 62 & 7.6 & 3.3 & 18.9 & 1.6 \\
\hline Prop. of pop. in households with bathroom and piped water & 62 & 36.2 & 16.0 & 83.6 & 9.5 \\
\hline Prop. of pop. in households with garbage collection & 62 & 80.3 & 19.8 & 100.0 & 0.1 \\
\hline Human Development Index (HDI) & 62 & 0.56 & 0.1 & 0.7 & 0.4 \\
\hline Proportion of urban population & 62 & 54.9 & 14.3 & 99.5 & 4.2 \\
\hline \multicolumn{6}{|l|}{ Meteorological and river quota } \\
\hline Average wind speed & 62 & 0.9 & 0.4 & 1.8 & 0.1 \\
\hline Annual average heat stroke & 62 & 156.0 & 19.8 & 193.5 & 121.9 \\
\hline Average days with precipitation & 62 & 15.8 & 1.7 & 18.9 & 12.6 \\
\hline Annual average rainfall & 62 & 215.3 & 23.5 & 253.5 & 167.9 \\
\hline Average minimum temperature & 62 & 23.2 & 0.9 & 25.0 & 21.4 \\
\hline Average maximum temperature & 62 & 32.8 & 0.4 & 33.8 & 32.1 \\
\hline Average relative humidity & 62 & 84.5 & 2.1 & 87.3 & 79.8 \\
\hline Average temperature compensated & 62 & 27.0 & 0.5 & 28.0 & 26.1 \\
\hline Average of the maximum quota & 62 & 1181.0 & 470.0 & 2653.0 & 425.2 \\
\hline Average of the minimum quota & 62 & 960.7 & 469.8 & 2482.5 & 316.2 \\
\hline Average of the middle quota & 62 & 1068.9 & 469.3 & 2553.2 & 382.6 \\
\hline \multicolumn{6}{|l|}{ Vector Control } \\
\hline Proportion of goals reached from home visits & 62 & 26.1 & 29.3 & 88.1 & 0 \\
\hline Number of years with a target of 5 home visits reached ${ }^{a}$ & 62 & 0.4 & 0.8 & 3 & 0 \\
\hline Number of years with infestation ${ }^{a}$ & 62 & 2.2 & 2.4 & 5 & 0 \\
\hline Appropriate ratio of the number of agents per property & 62 & 0.3 & 0.5 & 1 & 0 \\
\hline Appropriate ratio of the number of supervisors to health agent & 62 & 0.6 & 0.5 & 1 & 0 \\
\hline Adequacy of the number of supervisors and agents for amount of building & 62 & 1.1 & 1.4 & 3 & 0 \\
\hline Household infestation mean index for the period & 62 & 0.5 & 0.9 & 3.6 & 0 \\
\hline Number of years with household infestation mean index higher than 1\% & 62 & 0.6 & 1.1 & 4 & 0 \\
\hline
\end{tabular}

${ }^{\mathrm{a}}$ Recorded between 2006 and 2010

v.13 (StataCorp, 2013, College Station, Texas, USA) was used to perform these analyzes.

\section{Results}

Between 2001 and 2011, 85,216 cases of dengue fever were recorded in the Amazonas state. However, between 2010 and 2011, the largest epidemic occurred, resulting in 58,296 reported cases involving 49 (80\%) municipalities in the state.

During this epidemic, most of the municipalities recorded at least one monthly dengue incidence rate greater than 100 cases per 100,000 inhabitants (Fig. 2a) over at least one month. With the exception of the Alto
Solimões and Médio Amazonas regions, in all regions 2/ 3 or more of the municipalities were affected by the dengue epidemic (Fig. 2a-c). Extensive epidemics were observed in $35 \%(22 / 62)$ of municipalities, mostly located in Entorno de Manaus and Rio Negro region (55\% [11/20]) (Fig. 2d).

The socioeconomic and demographic profile of amazon municipalities shows a high average illiteracy rate (21\%), high percentage of poor population $(53 \%)$, and low human development index (0.56). The most populated municipalities are Manaus, with 1.8 million inhabitants in 2010, and Parintins, with 101 thousand inhabitants. The other municipalities have less than 90 
Table 3 Socioeconomic factors associated with extensive dengue epidemics using bivariate and multivariable hierarchical level analysis

\begin{tabular}{|c|c|c|c|c|}
\hline & Crude OR $(95 \% \mathrm{Cl})$ & $p$-value & $\begin{array}{l}\text { Adjusted OR }(95 \% \mathrm{Cl}) \\
\text { - Hierarchical levels }\end{array}$ & $p$-value \\
\hline Illiteracy rate & $0.9(0.9-1.0)$ & 0.151 & $0.9(0.8-1.1)$ & 0.202 \\
\hline Gini Index & $0.5(0-3848.1)$ & 0.868 & - & - \\
\hline Proportion of poor & $0.9(0.9-1.0)$ & 0.023 & $1.0(0.9-1.2)$ & 0.771 \\
\hline Per capita income & $1.0(1.0-1.1)$ & 0.011 & $1.0(1.0-1.1)$ & 0.011 \\
\hline Unemployment rate & $1.1(0.9-1.3)$ & 0.211 & - & - \\
\hline Proportion of population in households with bathroom and piped water & $1.0(1.0-1.1)$ & 0.022 & $1.0(0.9-1.1)$ & 0.610 \\
\hline Proportion of population in households with garbage collection & $1.0(0.9-1.1)$ & 0.106 & $1.0(0.9-1.1)$ & 0.440 \\
\hline $\mathrm{HDI}$ & $1.0(0.3-3.5)$ & 0.831 & $1.0(0.1-8.5)$ & 0.065 \\
\hline Proportion of urban population & $0.9(0.9-1.0)$ & 0.174 & $0.9(0.9-1.1)$ & 0.380 \\
\hline
\end{tabular}

HDI Human Development Index, OR Odds ratio

thousand inhabitants. Manaus has the highest population concentration in urban areas, with $99 \%$ of the urban population. In Parintins, the urban population corresponds to $68 \%$ of the total population. The meteorological feature results indicated a low wind speed $(0.9 \mathrm{~km} / \mathrm{h})$ and high precipitation rate $\left(215.3 \mathrm{~mm}^{3}\right)$. The river quota recorded in the municipalities presented a considerable variation, ranging from a minimum average quota of $316 \mathrm{~cm}$ to a maximum average quota of $2653 \mathrm{~cm}$. The municipalities of Amazonas are characterized by a high household vector infestation and an insufficient number of health agents and supervisors. Generally, the less populous municipalities present a recent history of Aedes infestation and lower average rates of infestation (Table 2).

The proportion of poor, per capita income, and proportion of the population in households with bathroom/ piped water were associated with the extensive dengue epidemics. When considering this level alone, an increase of one unit in per capita income increased the risk of severe epidemic occurrence by $1 \%$ (adjusted OR $=1.1,95 \%$ CI: $1.0-1.1$ ), after controlling for the other variables of this level (Table 3).

No meteorological and hydrology hierarchical level factors were significantly associated with EDE occurrence. However, the average number of days with precipitation, when adjusted for other conditions, increased the risk of EDE (adjusted OR = 1.4, 95\% CI: 1.1-1.9), (Table 4).

The operational level model showed the number of years with infestation, adequate ratio of number of agents per property, adequate ration of supervisors and agents per building, household infestation mean index for the period, and number of years with household infestation mean index greater than $1 \%$ as predictors of EDE. Controlling for confounders, the risk of EDE increased by $54 \%$ with each increase by one unit in the number of years with infestation (adjusted OR $=1.5,95 \%$ CI: 1.2-2.0), (Table 5).

The final multivariable model revealed a significant association between EDE occurrence and the average

Table 4 Meteorological and hydrological factors associated with extensive dengue epidemic using bivariate and multivariable hierarchical level analysis

\begin{tabular}{|c|c|c|c|c|}
\hline & Crude OR (95\% CI) & $p$-value & $\begin{array}{l}\text { Adjusted OR }(95 \% \mathrm{Cl}) \\
\text { - Hierarchical levels }\end{array}$ & $p$-value \\
\hline Average wind speed & $2.9(0.8-10.2)$ & 0.092 & $31.7(0.15-6521.4)$ & 0.092 \\
\hline Annual average heat stroke & $1.0(1.0-1.1)$ & 0.052 & $0.9(0.8-1.1)$ & 0.486 \\
\hline Average days with precipitation & $1.4(0.9-2.0)$ & 0.057 & $1.4(1.1-1.9)$ & 0.018 \\
\hline Annual average rainfall & $1.0(0.9-1.0)$ & 0.993 & - & - \\
\hline Average minimum temperature & $1.6(0.8-2.9)$ & 0.137 & $0.1(0.1-3.7)$ & 0.159 \\
\hline Average maximum temperature & $0.9(0.2-3.5)$ & 0.875 & - & - \\
\hline Average relative humidity & $0.9(0.7-1.2)$ & 0.640 & - & - \\
\hline Average compensated temperature & $2.2(0.8-6.1)$ & 0.133 & $5477.3(0.5-5555.6)$ & 0.064 \\
\hline Average of the maximum quota & $1.0(1.0-1.1)$ & 0.052 & $1.5(0.2-15.8)$ & 0.741 \\
\hline Average of the minimum quota & $1.0(1.0-1.1)$ & 0.052 & $1.1(1.0-1.2)$ & 0.144 \\
\hline Average of the middle quota & $1.0(1.0-1.1)$ & 0.052 & $6.85(0.75-62.98)$ & 0.089 \\
\hline
\end{tabular}


Table $\mathbf{5}$ Vector control activities associated with extensive dengue epidemic using bivariate and multiple logistic regression analysis

\begin{tabular}{|c|c|c|c|c|}
\hline & $\begin{array}{l}\text { Crude Odds Ratio } \\
(95 \% \mathrm{Cl})\end{array}$ & $p$-value & $\begin{array}{l}\text { Adjusted Odds Ratio } \\
(95 \% \mathrm{Cl})\end{array}$ & $p$-value \\
\hline Average proportion of goals reached from home visits & $1.0(1.0-1.1)$ & 0.121 & $0.9(0.9-1.0)$ & 0.100 \\
\hline Number of years with an achieved target of 5 home visits & $1.8(0.9-3.5)$ & 0.075 & $3.5(0.8-15.7)$ & 0.107 \\
\hline Number of years with infestation & $1.5(1.2-2.0)$ & 0.001 & $1.5(1.2-2.0)$ & 0.001 \\
\hline Appropriate ratio of the number of agents per property & $4.8(1.5-15.1)$ & 0.007 & $495.8(0.1-1260.0)$ & 0.410 \\
\hline Appropriate ratio of the number of supervisors to health agent & $2.7(0.9-8.2)$ & 0.087 & $0.3(0.1-3.9)$ & 0.352 \\
\hline Adequate ration of supervisors and agents per building & $1.8(1.2-2.7)$ & 0.004 & $0.1(0.1-63.9)$ & 0.520 \\
\hline Household infestation mean index for the period & $2.3(1.2-4.5)$ & 0.013 & $1.6(0.3-7.2)$ & 0.567 \\
\hline Number of years with household infestation mean index greater than $1 \%$ & $1.8(1.1-3.1)$ & 0.020 & $1.8(0.5-5.9)$ & 0.355 \\
\hline
\end{tabular}

number of days with precipitation and the number of years with infestation. The risk of EDE increased by $40 \%$ as the average number of days with precipitation increased by one unit (adjusted OR $=1.4$, 95\% CI: $1.1-$ 1.9). Moreover, the risk increased by $53 \%$ as the number of years with infestation increased by one unit (adjusted $\mathrm{OR}=1.5$, 95\% CI: 1.2-2.0) when controlling for the average number of days with precipitation (Table 6).

\section{Discussion}

In areas where dengue is considered endemic, it is likely that larger epidemics may play a relevant role in the spread of disease and health status of these populations. Here, three features of the epidemics were evaluated in order to classify them according to epidemic dimensions. Only the larger epidemics, classified as extensive epidemics, were evaluated in this study to examine epidemic distribution and associated factors. Several authors use epidemic metrics to characterize dengue outbreaks [11, 12, 15, 21]. According to Galli and Chiaravalloti Neto [22], the use of these epidemic indices as an alternative to the use of the incidence rate allows the identification of areas and periods of greatest risk.

Among the 49 municipalities that recorded dengue cases in the study period, we identified 22 municipalities that met the criteria for extensive dengue epidemics, that is, this municipalities presented epidemics with high intensity, extent, and duration. These municipalities surround the Capital and the main economical centers of the State, including Coari, Tefé, and Parintins. Extensive dengue epidemics occurrence in these municipalities is likely to support the widespread dispersal of dengue cases in the region, revealing the potential for dissemination of other arboviruses, such as Zika and Chikungunya, as well as the complexity of controlling these diseases in the region. In areas with widespread disease distribution, it is important to differentiate the severity levels of the areas affected by the disease. This approach allows investigate with greater precision the etiological factors of large epidemics, and also it is an important tool for public managers and decision makers, since they generate alerts with different risk levels.

Multivariable analysis results indicate that climatic and environmental conditions, as well as vector control activities, has independent effects on occurrence of extensive dengue epidemics in the Amazonas municipalities.

The urbanization process triggered by economic development may favor the establishment and spread of the Aedes mosquito, due to its ability to adapt to urban environments [21]. Furthermore, population mobility facilitates viral circulation and the climate changes generated in this space enhance disease transmission cycle [23]. Our results corroborate this hypothesis as the risk of extensive dengue epidemics is higher in the municipalities with higher economic development, characterized by higher average per capita income, a larger proportion of the population living in households with toilets and water supply, and lower proportion of poor population. Even when controlling for other socioeconomic conditions, average per capita income was associated with the occurrence of extensive epidemics.

Seasonal climatic forecasts are important tools for dengue epidemics prediction [24, 25]. The findings of this study show that an increase in insolation time, number of days with precipitation, and river quota, increased the risk of extensive dengue epidemics occurrence, presenting borderline $p$-value in the single regression model. Cazelles et al., studied synchronous dengue epidemics in 2005 and found a positive correlation between the incidence of dengue hemorrhagic fever and temperature and precipitation increase [26]. Other

Table 6 Extensive dengue epidemic predictors based on hierarchical multiple logistic regression analysis

\begin{tabular}{llc}
\hline & $\begin{array}{l}\text { Adjusted Odds } \\
\text { Ratio (95\% Cl) }\end{array}$ & p-value \\
\hline $\begin{array}{l}\text { Average number of days with } \\
\text { precipitation }\end{array}$ & $1.4(1.1-1.9)$ & 0.041 \\
\begin{tabular}{l} 
Number of years with infestation \\
\hline
\end{tabular} & $1.5(1.2-2.0)$ & 0.009 \\
\hline
\end{tabular}


studies also showed a positive association between these climate variables and river height with dengue [25, 27], demonstrating the consistency of our findings.

The National Dengue Control Programme in Brazil [18] advocates home visits to $100 \%$ of the properties every two months and, during epidemic periods, intensification of vector control actions in locations previously determined by the LIRAa (vector infestation rate surveys). Our results showed that municipalities with dengue epidemics had insufficient number of agents and supervisors and a high household infestation index. These findings support the hypothesis that structural problems in public health services, such as insufficient numbers of health agents, can lead to the non-execution of or failure to achieve target home visits, and, consequently, the increase of vector infestation rates in a given locality. As quoted by Gubler [28], most mosquito control actions focused on eliminating adult vectors, with an unsuitable method and, without changing people's lifestyles, they continue to provide habitats larvae in their homes. This may result in the vector's geographical expansion and increased mosquito population density, increased viral circulation and occurrence of cases and severe epidemics.

Precipitation and non-effective control measures were the best predictors of extensive epidemic risk, when considering proximal and distal levels. In our model, socioeconomic conditions may be understood as distal variables, influencing outcome to a lesser extent than the proximal ones, explaining why they were not included in the final model. This corroborates the results of other studies identifying an association between dengue epidemics and rainfall and household vector infestation [29-32]. Furthermore, socioeconomic factors (per capita income), other environmental factors (river water level) and other vector control measures adopted (adequacy of human resources for vector control level of building infestation) can also identify municipalities with a high propensity to extensive epidemics.

Secondary data obtained from the SINAN database were used in this study. There are generally issues with the underreporting, completeness and quality of this type of data. However, in this study only variables with at least $70 \%$ of completeness were considered. Searches for duplicates records were performed and dates were reviewed to identify any mistakes.

\section{Conclusions}

The findings presented here showed influences of local and regional climate variability on the occurrence of extensive dengue epidemics. These results can provide basic knowledge for the development of an early warning system in the future and support for decision makers implementing dengue prevention strategies under different environmental conditions. Furthermore, there is a strong need to integrate vector control, case management, epidemiological investigation, and health education, in order to respond to the growing threat of multiple mosquito-borne diseases, such as dengue, Zika, and chikungunya, highly prevalent in South American.

\section{Additional file}

Additional file 1: Structure of epidemic indicators, Epidemic indicators definition, units and scale. (DOCX $21 \mathrm{~kb}$ )

\section{Abbreviations}

Cl: Confidence interval; EDE: Extensive dengue epidemic; EM: Epidemic months; EW: Epidemic wave; FVS-AM: Health Surveillance Foundation; HDI: Human development index; IR: Incidence rate; Max: Maximum value; MEW: Municipalities with epidemic waves; Min: Minimum value; N: Sample size; OR: Odds ratio; PEM: Putative epidemic months; SD: Standard deviation; SINAN: Notifiable Diseases Information System; TMR: Total number of municipalities in the region; WHO: World Health Organization

\section{Acknowledgments}

We are grateful to the Center for Information Systems in Health Surveillance Foundation for Health of Amazonas for access to the SINAN database and to Luzia Melo Mustafa and Togny Mael Figueirdo Pinto for your contributions to this study.

\section{Funding}

This study was supported by government of the state of Amazonas, through the Fundação de Amparo à Pesquisa do Estado do Amazonas, FAPEAM (Research Foundation of the State of Amazonas), for granting scholarships. DBC is a fellow of the RH-Doctoral Program at FAPEAM. This work was funded by the National Council for Scientific and Technological Development (http://www.cnpq.br, grant 440856 / 2016-7) and Coordination for the Improvement of Higher Education Personnel (http://www.capes.gov.br, grants 88881.130825 / 2016-00 and 88887.130823 / 2016-00).

\section{Availability of data and materials}

The datasets supporting the conclusions of this article are available by request in the "Sistema Eletrônico do Serviço de Informação ao Cidadão" repository, [http://esic.cgu.gov.br/sistema/site/index.html] and the socioeconomics datasets analyzed during the current study are available in the "Departamento de Informática do SUS" repository, [http:// datasus.saude.gov.br/] and Human Development Atlas repository, [http:// www.atlasbrasil.org.br/2013/pt/consulta/].

\section{Authors' contributions}

DBC, VSS, BCA, RCP, MS, RAP, CFC, and JUB contributed to the conceptualization, resources, supervision, project administration, and funding acquisition; RCP, MS, RAP, and CFC made substantial contributions to acquisition of data and interpretation of data; DBC, VSS, and JUB contributed to the programming and data curation; DBC, VSS, and JUB contributed to the validation, formal analysis, investigation, and visualization; DBC, VSS, and JUB contributed to the design of methodology; DBC, VSS, BCA, RCP, MS, RAP CFC, and JUB contributed to writing and editing original draft, and revise the manuscript. All authors read and approved the final manuscript.

Ethics approval and consent to participate

This study was approved by the Institutional Review Board of the Adriano Jorge Foundation Hospital, under protocol number 1162956, on July 72015. The institutional review board waived the need for written informed consent from participants as the study involved only secondary data and the confidentiality of the patients' identities was protected.

Consent for publication

Not applicable. 


\section{Competing interests}

The authors declare that they have no competing interests.

\section{Publisher's Note}

Springer Nature remains neutral with regard to jurisdictional claims in published maps and institutional affiliations.

\section{Author details}

${ }^{1}$ Fundação de Vigilância em Saúde do Amazonas, Manaus, Brazil. ${ }^{2}$ Escola Nacional de Saúde Pública Sérgio Arouca - Fiocruz, Rio de Janeiro, Brazil. ${ }^{3}$ Fundação de Medicina Tropical Dr Heitor Vieira Dourado - FMT-HVD Manaus, Brazil. ${ }^{4}$ Instituto Oswaldo Cruz - Fiocruz, Rio de Janeiro, Brazil. ${ }^{5}$ Instituto de Medicina Social - UERJ, Rio de Janeiro, Brazil. ${ }^{6}$ PECTI-SAÚDE / Fundação de Amparo a Pesquisa do Estado do Amazonas, Manaus, Brazil.

\section{Received: 2 August 2017 Accepted: 2 March 2018}

\section{Published online: 15 March 2018}

\section{References}

1. Rigau-Pérez JG, Clark GG, Gubler DJ, Reiter P, Sanders EJ, Vorndam AV. Dengue and denque haemorrhagic fever. Lancet. 1998;352:971-7.

2. Kalayanarooj S, Vaughn DW, Nimmannitya S, Green S, Suntayakorn S, Kunentrasai N, et al. Early clinical and laboratory indicators of acute dengue illness. J Infect Dis. 1997;176:313-21.

3. Cobra C, Rigau-Pérez JG, Kuno G, Vorndam V. Symptoms of dengue fever in relation to host immunologic response and virus serotype, Puerto Rico, 1990-1991. Am J Epidemiol. 1995;142(11):1204

4. Pan American Health Organization. Dengue and dengue hemorrhagic fever in the Americas: guidelines for prevention and control. Washington, DC: Panamerican Health Organization, Scientific Publication; 1994. p. 548.

5. WHO. Global strategy for dengue prevention and control 2012-2020. Geneva: World Health Organization; 2012.

6. Brathwaite Dick O, San Martín JL, Montoya RH, del Diego J, Zambrano B, Dayan GH. The history of denque outbreaks in the Americas. Am J Trop Med Hyg. 2012;87:584-93.

7. Ríos-Velásquez CM, Codeço CT, Honório NA, Sabroza PS, Moresco M, Cunha $\mathrm{ICL}$, et al. Distribution of dengue vectors in neighborhoods with different urbanization types of Manaus, state of Amazonas, Brazil. Mem Inst Oswaldo Cruz. 2007;102:617-23.

8. Pinheiro VCS, Tadei WP. Frequency, diversity, and productivity study on the Aedes aegypti most preferred containers in the city of Manaus, Amazonas, Brazil. Rev Inst Med Trop São Paulo. 2002;44:245-50.

9. Mde S B, Figueiredo RM, Ramasawmy R, Itapirema E, Gimaque JBL, Santos LO, et al. Simultaneous circulation of all four dengue serotypes in Manaus, state of Amazonas, Brazil in 2011. Rev Soc Bras Med Trop. 2012:45:393-4.

10. Cummings DAT, Irizarry RA, Huang NE, Endy TP, Nisalak A, Ungchusak K, et al. Travelling waves in the occurrence of denque haemorrhagic fever in Thailand. Nature. 2004;427:344-7.

11. Parker D, Holman D. Event history analysis of dengue fever epidemic and inter-epidemic spells in Barbados, Brazil, and Thailand. Int J Infect Dis. 2012; 16(11):e793-8.

12. Ritchie SA, Pyke AT, Hall-mendelin S, Day A, Mores CN, Christofferson RC, et al. An explosive epidemic of DENV-3 in cairns, Australia. PLoS One. 2013;8: e68137.

13. Res C, Hopp MJ, Foley JA. Worldwide fluctuations in dengue fever cases related to climate variability. Climate Res. 2003;25:85-94.

14. Hales S, Hales S, de Wet N, Maindonald J, Woodward A. Potential effect of population and climate changes on global distribution of dengue fever: an empirical model. Lancet. 2002;360(9336):830-4.

15. Wen $\mathrm{T}$, Lin NH, Lin C, King C, Su M. Spatial mapping of temporal risk characteristics to improve environmental health risk identification: A case study of a dengue epidemic in Taiwan. Sci Total Environ. 2006;367:631-40.

16. IBGE. Censo Demográfico 2010 - Características da população e dos domicílios - Resultados do universo. Rio de Janeiro: Instituto Brasileiro de Geografia e Estatística; 2011.

17. Alvares CA, Stape JL, Sentelhas PC, de Moraes Gonçalves JL, Sparovek G. Köppen's climate classification map for Brazil. Meteorol Z. 2013:22·711-28.

18. Brazilian Ministry of Health. Diretrizes Nacionais para Prevenção e controle de Epidemias de Dengue. Brasilia: Ministry of Health, Department of Health Surveillance, Department of Epidemiological Surveillance; 2009. p. 160.
19. IBGE. Projeções da População. Brasil e unidades da federação. Rio de Janeiro: Instituto Brasileiro de Geografia e Estatística; 2013.

20. Bowman LR, Runge-Ranzinger S, McCall PJ. Assessing the relationship between vector indices and dengue transmission: a systematic review of the evidence. PLoS Negl Trop Dis. 2014;8:e2848.

21. Barcellos C, Lowe R. Expansion of the dengue transmission area in Brazil: the role of climate and cities. Tropical Med Int Health. 2014;19:159-68.

22. Galli B, Chiaravalloti NF. Temporal-spatial risk model to identify areas at highrisk for occurrence of dengue fever. Rev Saúde Pública. 2008:42:656-63.

23. Jetten TH, Focks DA. Potential changes in the distribution of dengue transmission under climate warming. Am J Trop Med Hyg. 1997:57:285-97.

24. Câmara FP, Gomes AF, dos Santos GT, Câmara DCP. Clima e epidemias de denque no Estado do Rio de Janeiro. Rev Soc Bras Med Trop. 2009:42:137-40.

25. Lowe R, Bailey TC, Stephenson DB, Jupp TE, Graham RJ, Barcellos C, et al. The development of an early warning system for climate-sensitive disease risk with a focus on dengue epidemics in Southeast Brazil. Stat Med. 2013; 32:864-83.

26. Cazelles B, Chavez M, Mcmichael AJ, Hales S. Nonstationary influence of el Niño on the synchronous dengue epidemics in Thailand. PLoS Med. 2005;2:e106

27. Adde A, Roucou P, Mangeas M, Ardillon V, Desenclos J-C, Rousset D, et al. Predicting dengue fever outbreaks in French Guiana using climate indicators. PLoS Negl Trop Dis. 2016;10(4):e0004681.

28. Gubler DJ. Dengue, Urbanization and globalization: the unholy trinity of the 21st century. Trop Med Health. 2011;39:3-11.

29. Koopman JS, Prevots DR, Mann MAV, Dantes HG, Aquino MLZ, Longini IM, et al. Determinants and predictors of dengue infection in Mexico. Am J Epidemiol. 1991;133:1168-78.

30. Vargas WP, Kawa H, Sabroza PC, Soares VB, Honório NA, de Almeida AS. Association among house infestation index, dengue incidence, and sociodemographic indicators: surveillance using geographic information system. BMC Public Health. 2015;15

31. Johansson MA, Cummings DAT, Glass GE. Multiyear climate variability and dengue-el Niño southern oscillation, weather, and dengue incidence in Puerto Rico, Mexico, and Thailand: a longitudinal data analysis. PLoS Med. 2009;6:e1000168.

32. Fan J, Lin H, Wang C, Bai L, Yang S, Chu C, et al. Identifying the high-risk areas and associated meteorological factors of dengue transmission in Guangdong Province, China from 2005 to 2011. Epidemiol Infect. 2014:142:634-43.

\section{Submit your next manuscript to BioMed Central and we will help you at every step:}

- We accept pre-submission inquiries

- Our selector tool helps you to find the most relevant journal

- We provide round the clock customer support

- Convenient online submission

- Thorough peer review

- Inclusion in PubMed and all major indexing services

- Maximum visibility for your research

Submit your manuscript at www.biomedcentral.com/submit
Biomed Central 